\title{
Reliability of the Brownish-flanked Bush Warbler's soft song in male-male conflict
}

\author{
Canwei Xia ${ }^{1}$, Boye Liu', Daiping Wang ${ }^{1}$, Huw Lloyd ${ }^{2}$ and Yanyun Zhang ${ }^{1 *}$
}

\begin{abstract}
Background: Soft song is a low-amplitude song produced by many birds. Recent studies have confirmed that soft song is an aggressive signal. For example, the Brownish-flanked Bush Warblers Cettia fortipes use soft song in male-male conflicts, particularly prior to attacks. Although stable signaling systems require that signals be honest on average, models predict that cheating is an acceptable strategy for some individuals or in some contexts.

Methods: This study aimed to test the reliability of soft song as an aggressive signal in the brownish-flanked bush warbler. We used mounted specimens accompanied by broadcast songs or soft songs to simulate a male attempting to invade an existing territory.

Results: We found the mounted specimen that coupled playback of soft songs suffered more and quicker attacks from the territory owner and that the relationship between soft song and subsequent attack in the territory owner was far from perfect. We observed territory owners that both over-signaled (i.e., produced soft song but did not attack) and under-signaled (i.e., attacked without producing soft song). Under-signaling territory owners were relatively more commonly than were over-signaling territory owners, particularly in simulated intrusion that coupled playback of soft song with a mount specimen.

Conclusions: We discuss the cost of producing soft song and the potential benefit of the unreliable use of soft song and propose a new hypothesis for under-signaling with soft song; i.e., under-signaling territory owners might benefit from taking the initiative in fights.
\end{abstract}

Keywords: Aggressive signal, Brownish-flanked Bush Warbler, Cost, Reliability, Soft song

\section{Background}

Most signals are thought to be reliable based on the underlying logic that receivers only respond to signals that are sufficiently reliable (Maynard and Harper 2003; Searcy and Nowicki 2005). If a signal is always unreliable, the receivers would ignore that signal. Thus, the signaling systems would not exist at all. When the signaler's and receiver's interests are opposed (e.g., in male-male competition for resources), there are two main explanations for the reliability of signals. First, some signals are reliable because those signals are forced to be honest due to physiological or anatomical constraints on signal production (Maynard and Parker 1976). For example, the dominant frequencies of calls

\footnotetext{
*Correspondence: zhangyy@bnu.edu.cn

${ }^{1}$ Ministry of Education Key Laboratory for Biodiversity and Ecological Engineering, College of Life Sciences, Beijing Normal University, Beijing 100875, China

Full list of author information is available at the end of the article
}

used in male-male conflict in some frogs belongs in this category; the frequency is determined by the size of the vocal apparatus, which is determined by body size, and the dominant frequency is thus constrained to reflect reliable information about body size (Martin 1971, 1972). A performance constraint on the trilled vocalizations in Emberizidae is an additional example: maximal values of frequency bandwidth and trill rates are limited by motor constraint (Podos 1996, 1997). The second explanation for signal reliability is based on costs. Costs that stem from signaling can prevent deceit if the signaler's fitness is decreased due to cheating (Grafen 1990). Birds often use vocal signals in territorial disputes, and the vocal signal used here might be associated with escalated contests (Searcy and Beecher 2009). If a weak individual cannot bear an escalated contest, reliable vocal signals could guarantee the cost of a conceivable escalated contest (Vehrencamp 2000; Molles and Vehrencamp 2001). 
Although signals are often honest, unreliable signaling can exist in signaling systems (Maynard and Harper 2003; Searcy and Nowicki 2005). Unreliable signaling can be defined by departures from the typical correlation between the signal and an attribute of the signaler (Hauser 1996). For example, If signal $a$ is typically correlated with action A, unreliable signaling occurs when an individual signals $a$ but does not perform A (i.e., over-signaling) or does not signal $a$ but does perform A (i.e., undersignaling). Depending on the value of the contested resource and the expected cost of an escalated contest for the signaler, models predict that unreliable signaling can be a useful strategy for some individuals or in some context (Szamado 2000; Szalai and Szamado 2009). For example, although song type matching (i.e., singing to the rival with the same song that the rival has just sung) has long be seen as an aggressive signal in song sparrows during male-male conflict (Stoddard et al. 1992), this signal can reflect the signaler's expectation of an escalated contest in the initial of territory conflict but fail to predict direct attack (Searcy et al. 2006; Akcay et al. 2013). Because the reliability of a signal is context dependent, testing the signal in different contexts might aid the understanding of both the function of the signal and the evolution of the signaling system.

Soft song is characterized by markedly lower amplitudes than normal song (here termed broadcast song) and has long been observed in many birds (Dabelsteen et al. 1998; Morton 2000). Recent studies have confirmed that soft song is an aggressive signal; soft song can predict aggressive escalation in both passerine (Searcy et al. 2006; Ballentine et al. 2008; Hof and Hazlett 2010; Akcay et al. 2011) and non-passerine birds (Rek and Osiejuk 2011). Additionally, playback experiments with mounted specimens have shown that soft song is a reliable aggressive signal in male-male conflict (Searcy and Beecher 2009; van Staaden et al. 2011; Searcy et al. 2014). In a previous study, we found that the relationship between soft song production and subsequent attack is significant in the Brownish-flanked Bush Warbler Cettia fortipes (Xia et al. 2013b). Here, we examined the correlation between soft song production and subsequent attack in different male-male conflict contexts in this species.

The brownish-flanked bush warbler is a small, furtive passerine found throughout Southeast Asia. During the breeding season, the males sing clear, high-pitched broadcast songs from dense undergrowth (del Hoyo et al. 2006; Kennerley and Pearson 2010). The males have a small repertoire of broadcast songs (typically two or three songs) and always sing the broadcast song types in alternating patterns (e.g., a-b-a-b; Xia et al. 2013a). Compared to broadcast song, soft song in this species is characterized by lower amplitude, a significantly lower minimum frequency, more notes, a longer duration, and a higher note rate (Xia et al. 2013b). Thus, soft song is easily distinguished from broadcast song in the field. Based on our observations, broadcast song is always used in spontaneous singing and after expelling an intruder, while soft song is used during encounters between rival males. In a previous playback study (Xia et al. 2013b), we used mounted specimens positioned within the territory of subject males and conducted playback trails of broadcast songs and found that six of 25 territorial owners attacked the mounted specimen, and all attacking subjects generated soft songs immediately prior to the attacks. However, the context of the playback experiment of Xia et al. (2013b) is uncommon in the field because in contrast to broadcast song, soft song was always produced by the intruder when in close contact with the territory owner. The first aim of this study was to investigate whether soft song and subsequent attack are correlated in the territorial owner when the intruder produces soft song. The context of this study is more similar to that of the field when the territory owner closely encounters the intruder. Thus, this context can provide additional information about the function of soft song for birds.

The second aim of this study was to investigate the cost of soft song in the Brownish-flanked Bush Warbler. For signals with no obvious physiological or anatomical constraints, cost should be the most probable explanation for the stability of the signaling system (Vehrencamp 2000; Molles and Vehrencamp 2001). A previous study showed that soft song can induce male brownish-flanked bush warbler to spend significantly more time near the loudspeaker (Xia et al. 2013b). We hypothesized that closeness is a cost to the signaler in the experiment detailed by Xia et al. (2013b) based on the underlying logic that increasing closeness increases the possibility of attack. However, this underlying logic has not been verified in this species. In the present study, we show direct evidence of cost to the soft song signaler; i.e., soft songs induced more attacks.

\section{Methods}

\section{Study area and species}

During May 2013 we conducted experiments on a population of brownish-flanked bush warblers in the Dongzhai National Nature Reserve in the Henan province of southern China $\left(31.9^{\circ} \mathrm{N}, 114.3^{\circ} \mathrm{E}\right)$. The males in this population have been monitored, color-banded and recorded as a part of a long-term study since 2007. Brownish-flanked bush warblers defend territories from March to July. Most of the territories are characterized by dense bushes that are dominated by Camellia sinensis tea plants; thus, the territory boundaries are typically well defined by the habitat. 


\section{Song stimuli}

The songs used in the playback experiments were recorded using a TASCAM HD-P2 portable digital recorder (Tascam Co., Japan) and a Sennheiser MKH416P48 external directional microphone (Sennheiser Co., Germany) at a sampling rate of $44.1 \mathrm{kHz}$ and a sample size of 16 bits. For the playback trials, we randomly selected five broadcast songs that were recorded from five different males during the 2011 breeding season and five soft songs that were randomly selected from five different males recorded during the 2012 breeding season. We used Goldwave 5.25 (GoldWave Inc., Canada) to adjust the broadcast song rate to one song every $10 \mathrm{~s}$, which is similar to the song rate of this species. For the soft songs, we repeated the recordings to achieve a total time of 3 min because the majority of the soft song recordings were shorter than $3 \mathrm{~min}$. Using a CEL-240 sound level meter (Casella Co., USA), the speaker volume for the playback trials of the broadcast and soft songs were adjusted to $80 \mathrm{~dB}$ and $60 \mathrm{~dB}$, respectively, at a distance of $1 \mathrm{~m}$ above the speaker. This amplitude approximates the natural amplitude of song in the field as evaluated by ear by observers. In total, we used ten unique 3-min playback stimuli that included five broadcast songs and five soft songs. Similar playback stimuli have been used in a previous playback study of the species (see Xia et al. 2013b).

\section{Playback procedure}

We used mounted specimens of four male brownishflanked bush warblers obtained with permission from the Museum of Beijing Normal University, and we randomly selected one for each subject male. Prior to each playback trial, we located each subject male by its spontaneous singing behavior. We positioned a single mounted specimen on the ground concealed under bushes within the territory of each subject male at approximately $10 \mathrm{~m}$ from the singing spot. The specimens were always placed away from the territorial boundary to decrease the effects on neighbors. Playback was conducted using uncompressed wav files stored on a TeclastX18Mp3 player (Teclast Co., Shenzhen, China) connected to a Senway loudspeaker (Senway Amplifier Co., Shenzhen, China). The loudspeaker was placed next to the mounted specimen and concealed with grass or dead leaves.

There were 51 subject males used in this study. Each subject male was exposed to one playback trial. The type of playback (either broadcast or soft song playback) was determined by a coin toss for the first subject and was then alternated between broadcast song and soft song for the subsequent subject males. The specific broadcast or soft song playback stimuli were randomly selected for each subject male. Most of the males in this population have been color-banded, which allowed us to ensure that the playback stimuli were not recorded from the subject male or its immediate neighbors. Two observers, positioned approximately $10 \mathrm{~m}$ away from the mounted specimen, recorded the behavioral responses of the subject males. We stopped playback if the subject male began to physically attack the mounted specimen. Otherwise, the experiment continued for the $3 \mathrm{~min}$ duration. If a subject male did not appear within $3 \mathrm{~m}$ during the $3 \mathrm{~min}$ playback, we abandoned the trial because we could not be sure that the subject male had seen the mounted specimen. If the $3 \mathrm{~m}$ criterion was met, we recorded the attack latency, which was defined as the time from which the male first appeared within $3 \mathrm{~m}$ of the mounted specimen to attack (defined as any physical contact with the mount specimens). Due to difficulties in observing some behaviors (e.g., wing quivering) in the dense vegetation of the birds' habitat, we only recorded whether soft song was produced for each subject male. Because most attack latencies were $<10 \mathrm{~s}$ in our previous study (Xia et al. 2013b), we were only concerned with signals that occurred within $10 \mathrm{~s}$ prior to the attack. For those subjects that did not attack, we focused on the signals in the last $10 \mathrm{~s}$ within $3 \mathrm{~m}$ of the mounted specimens during 3 min playback. We obtained data from 51 subjects that included 26 subjects in the broadcast songs playback group and 25 subjects in the soft songs playback group.

\section{Data analysis}

We used Fisher's exact test to compare the numbers of attacks by the subject males between the broadcast song playback group and the soft song playback group. After we removed the data for the subject males that did not attack the mount specimen, a $t$ test was used to compare the attack latency between the broadcast song playback group and soft song playback group. To test the relationship between soft song and subsequent attack, we used Fisher's exact tests for the broadcast song playback group and the soft song playback group, respectively.

All data are expressed as the mean \pm the SE, and differences were considered significant at $P<0.05$. The data were analyzed using SPSS v.20 (IBM Co., New York, NY, USA). Permission for this study was granted by the National Bird-banding Center of China (license number H20110042) and the Dongzai National Nature Reserve (license number 2011002).

\section{Results}

The relationship between soft song and subsequent attack was significant in the broadcast song playback group (Fisher exact test, $P=0.046$ ) but not in the soft song playback group (Fisher exact test, $P=0.202$; Table 1). Both under-signaling and over-signaling subject 
Table 1 Number of subject males to $3 \mathrm{~min}$ of playback of broadcast or soft songs

\begin{tabular}{llll}
\hline Responses & & Playback broadcast songs & Playback soft songs \\
\hline Attack on specimen & Produced soft songs & 6 & 11 \\
& No soft song & 4 & 7 \\
No attack & Produced soft songs & 3 & 2 \\
& No soft song & 13 & 5 \\
\hline
\end{tabular}

males were observed. In broadcast song playback group, $15.4 \%$ subject males attacked without producing soft song (under-signaling) and $11.5 \%$ subject males produced soft song but did not attack (over-signaling); in soft song playback group, $28.0 \%$ subject males attacked without producing soft song (under-signaling) and 8.0\% subject males produced soft song but did not attack (over-signaling) (Table 1).

The soft song playback group evoked significantly more attacks than did the broadcast song playback group (Fisher exact test, $P=0.025$; Table 1 ), and the attack latency was significantly shorter in the soft song playback group $(23.2 \pm 7.9 \mathrm{~s})$ than in the broadcast song playback group $\left(59.9 \pm 16.7 \mathrm{~s} ; t\right.$ test, $t_{26}=2.252, P=$ 0.033; Figure 1).

\section{Discussion}

\section{Reliability of soft song}

Although the signal must be sufficiently reliable to maintain a stable signaling system, there is room for cheating as a strategy for some individuals or in some context (Szamado 2000; Szalai and Szamado 2009). In this study, we found that the correlation of the subject males' soft

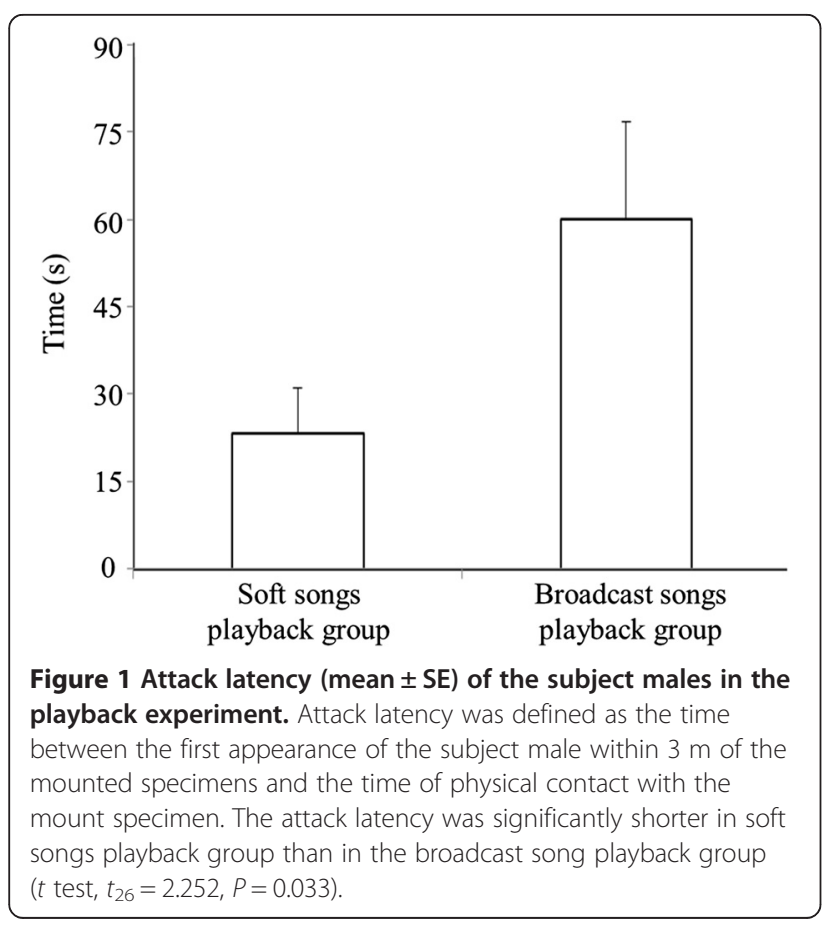

songs and subsequent attacks was significant in the broadcast song playback group but not in the soft song playback group. The reliability of an aggressive signal requires a correlation between the signal and an escalation toward physical fighting on the part of the signaler (Hauser 1996; Searcy and Nowicki 2005). Our data show that there was less reliability in the soft song playback group.

Can the subject males benefit from the unreliable signaling? There were two males in the broadcast song playback group and three males in the soft song playback group that produced soft song but did not attack the intruder (i.e., the mounted specimen). The potential benefit of this over-signaling is intimidation of the intruder that could cause the intruder to concede (Searcy and Nowicki 2005; Maynard and Harper 2003). Comparison of the attack rates of the soft song playback group $(72.0 \%)$ and the broadcast song playback group (38.5\%) indicates that soft songs from the intruder (mounted specimen) did not cause more territory owners to concede. However, we should note the asymmetry between the intruder and the territory owner (Maynard and Price 1973). Territory is always more valuable for the territory owner, thus it is not easy for the territory owner to be intimidated by the soft song of an intruder. Whether over-signaling benefits the territory owner remains an open question because the intruder (mounted specimen) could not retreat in our experiment. There were four males in the broadcast song playback group and seven males in soft song playback group that did attack the intruder (mounted specimen) but did not produce soft song. We believe that the potential benefit acquired by these under-signaling subject males was gaining the initiative in fighting. Based on this hypothesis, we infer that under-signaling might occur more often when a fight is inevitable. Our data support this inference; more under-signaling subject males were observed in the soft song playback group (28.0\%) than in the broadcast song playback group (15.4\%). In the future, we will demonstrate that initiating attack is beneficial in fights, and we will then fully understand the benefit acquired by the under-signaling subject males.

Limited reliability for soft song is also found in other species, i.e. attack was not correctly predicted in about one third of the Song Sparrow Melospiza melodia males 
(Akcay et al. 2013). Similarly, under-signaling is more common than over-signaling (Searcy et al. 2006; Akcay et al. 2013). As how responses to intrusion may rely on attributes of responding animals themselves (Moseley et al. 2013), high quality individuals may adopt undersignaling strategy without bothering to waste time in signaling (Searcy et al. 2013). To test this hypothesis, fighting ability or/and aggressive intentions will be compared between under-signaling males and other males in future work.

\section{The cost of soft song}

Cost is crucial for the maintenance of aggressive signaling systems (Vehrencamp 2000; Molles and Vehrencamp 2001). If there is no cost for aggressive signaling, it is advantageous for individuals produce the maximal levels such signals during conflicts. If all individuals signal maximally, it will be difficult for the receivers to judge the signaler's aggressive intentions based on the information contained in that signal. Thus, the receivers would ignore the signal, and the signaling system could not exist.

Among several potential cost concern soft song (summarized in Akcay et al. 2011; Akcay and Beecher 2012), receiver-retaliation cost get most support (Ballentine et al. 2008; Hof and Hazlett 2010; Anderson et al. 2012; Templeton et al. 2012). Receiver-retaliation cost posits that soft song increases the likelihood of the receiver retaliating aggressively. In a previous study, we found that soft song induces subject males to spend more time near the sound source (i.e., loudspeaker; Xia et al. 2013b) and inferred that being closer might indicate an increased possibility of attack. Recent studies have found that some behaviors that were previously thought to reflect attack intent are not actually correlated with attack (Ballentine et al. 2008; Hof and Hazlett 2010; Searcy et al. 2006). Thus, it is insufficient to assume that the closeness of the receiver is a cost of to the soft song signaler (Hof and Hazlett 2010; Hof and Podos 2013). The present study showed that when soft song was played back, more subject males conducted attacks of the mounted specimen with shorter attack latencies. The greater number of subject males attacking on mounted specimen indicates greater harm due to fighting to the signaler, and the shorter attack latency indicates that the signaler had less time for retreat. Both these factors provide direct evidence regarding receiver-retaliation cost of soft song; i.e., signalers that produce soft song put themselves at risk for fighting.

Besides receiver-retaliation cost (Anderson et al. 2012; Templeton et al. 2012; Searcy et al. 2014), there is cost from potential intruder in the song sparrow: as soft songs are low in amplitude, a potential intruder might fail to hear a male who uses soft song in conflict and thus be more likely to intrude on the soft song signaler's territory (Searcy and Nowicki 2006). As increasing evidence indicates that territorial conflicts can be eavesdropped on by other potential rivals (Akcay et al. 2010; Sprau et al. 2012), future work should test whether brownish-flanked bush warbler soft song signalers experience a greater number of intrusions.

\section{Conclusions}

In this work, we showed the receiver-dependent costs entailed by the soft song of the Brownish-flanked Bush Warbler; i.e., the signaler that produces soft song suffer more and quicker attacks from the receiver. We observed both over-signaling and under-signaling male Brownish-flanked Bush Warblers. In simulated intrusion that coupled playback of soft song with a mount specimen, a greater number of territory owner directly attacked without producing soft song (under-signaling). We suggest that such under-signaling males might benefit from taking the initiative in fights.

\section{Competing interests}

The authors declare that they have no competing interests.

\section{Authors' contributions}

YYZ and CWX conceived and designed the experiments. CWX, DPW, BYL performed the experiments. CWX analyzed the data. YYZ, CWX, HL wrote or revise the manuscript. All authors read and approved the final manuscript.

\section{Acknowledgements}

This study was supported by National Natural Science Foundation of China (No.31172098) and the China Postdoctoral Science Foundation

(No.2014 M550026). We would like to thank Jiayu LIU for her help on field work.

\section{Author details}

${ }^{1}$ Ministry of Education Key Laboratory for Biodiversity and Ecological Engineering, College of Life Sciences, Beijing Normal University, Beijing 100875, China. ${ }^{2}$ Division of Biology and Conservation Ecology, School of Science and the Environment, Manchester Metropolitan University, Chester Street, Manchester M15GD, UK.

Received: 20 September 2014 Accepted: 11 March 2015

Published online: 15 April 2015

\section{References}

Akcay C, Beecher MD (2012) Signalling while fighting: further comments on soft song. Anim Behav 83:e1-e3

Akcay C, Reed VA, Campbell SE, Templeton CN, Beecher MD (2010) Indirect reciprocity: song sparrows distrust aggressive neighbours based on eavesdropping. Anim Behav 80:1041-1047

Akcay C, Tom ME, Holmes D, Campbell SE, Beecher MD (2011) Sing softly and carry a big stick: signals of aggressive intent in the song sparrow. Anim Behav 82:377-382

Akcay C, Tom ME, Campbell SE, Beecher MD (2013) Song type matching is an honest early threat signal in a hierarchical animal communication system. P Roy Soc Lond B Bio 280:20122517

Anderson RC, Searcy WA, Hughes M, Nowicki S (2012) The receiver-dependent cost of soft song: a signal of aggressive intent in songbirds. Anim Behav 83:1443-1448

Ballentine B, Searcy WA, Nowicki S (2008) Reliable aggressive signalling in swamp sparrows. Anim Behav 75:693-703

Dabelsteen T, McGregor PK, Lampe H, Langmore N, Holland J (1998) Quiet song in song birds: an overlooked phenomenon. Bioacoustics 9:89-105

del Hoyo A, Elliott A, Sargatal J (2006) Handbook of the birds of the world, vol. 11: old world flycatchers to old world warblers. Lynx Edicions, Barcelona 
Grafen A (1990) Biological signals as handicaps. J Theor Biol 144:517-546 Hauser MD (1996) The evolution of communication. MIT Press, Cambridge Hof D, Hazlett H (2010) Low-amplitude song predicts attack in a North American wood warbler. Anim Behav 80:821-828

Hof D, Podos J (2013) Escalation of aggressive vocal signals: a sequential playback study. P Roy Soc Lond B Bio 280:20131553

Kennerley P, Pearson D (2010) Reed and bush warblers. Christopher Helm, London

Martin WF (1971) Mechanics of sound production in toads of the genus Bufo: passive elements. J Exp Zool 176:273-276

Martin WF (1972) Evolution of vocalizations in the genus Bufo. In: Blair WF (ed) Evolution in the genus Bufo. University Texas Press, Austin, pp 279-309

Maynard SJ, Harper D (2003) Animal signals. Oxford University Press, Oxford

Maynard SJ, Parker GA (1976) The logic of asymmetric contests. Anim Behav 24:159-175

Maynard SJ, Price GR (1973) The logic of animal conflict. Nature 246:15-18

Molles LE, Vehrencamp SL (2001) Songbird cheaters pay a retaliation cost: evidence for auditory conventional signals. P Roy Soc Lond B Bio 268:2013-2019

Morton ES (2000) An evolutionary view of the origins and functions of avian vocal communication. Jpn J Ornithol 49:69-78

Moseley DL, Lahti DC, Podos J (2013) Responses to song playback vary with the vocal performance of both signal senders and receivers. P Roy Soc Lond B Bio 280:20131401

Podos J (1996) Motor constraints on vocal development in a songbird. Anim Behav 51:1061-1070

Podos J (1997) A performance constraint on the evolution of trilled vocalizations in a songbird family (Passeriformes: Emberizidae). Evolution 51:537-551

Rek P, Osiejuk TS (2011) Nonpasserine bird produces soft calls and pays retaliation cost. Behav Ecol 22:657-662

Searcy WA, Beecher MD (2009) Song as an aggressive signal in songbirds. Anim Behav 78:1281-1292

Searcy WA, Nowicki S (2005) The evolution of animal communication: reliability and deception in signaling systems. Princeton University Press, Princeton

Searcy WA, Nowicki S (2006) Signal interception and the use of soft song in aggressive interactions. Ethology 112:865-872

Searcy WA, Anderson RC, Nowicki S (2006) Bird song as a signal of aggressive intent. Behav Ecol Sociobiol 60:234-241

Searcy WA, Anderson RC, Ballentine B, Nowicki S (2013) Limits to reliability in avian aggressive signals. Behaviour 150:1129-1145

Searcy WA, Akcay C, Nowicki S, Beecher MD (2014) Aggressive signaling in song sparrows and other songbirds. Adv Stud Behav 46:89-125

Sprau P, Roth T, Amrhein V, Naguib M (2012) Distance-dependent responses by eavesdroppers on neighbour-stranger interactions in nightingales. Anim Behav 83:961-968

Stoddard PK, Beecher MD, Campbell SE, Horning CL (1992) Song-type matching in the song sparrow. Can J Zool 70:1440-1444

Szalai F, Szamado S (2009) Honest and cheating strategies in a simple model of aggressive communication. Anim Behav 78:949-959

Szamado S (2000) Cheating as a mixed strategy in a simple model of aggressive communication. Anim Behav 59:221-230

Templeton CN, Akcay C, Campbell SE, Beecher MD (2012) Soft song is a reliable signal of aggressive intent in song sparrows. Behav Ecol Sociobiol 66:1503-1509

van Staaden MJ, Searcy WA, Hanlon RT (2011) Signaling aggression. In: Huber R, Bannasch DL, Brennan P (eds) Advances in genetics, vol 75. Academic, Burlington, pp 23-49

Vehrencamp SL (2000) Handicap, index, and conventional signal elements of bird song. In: Espmark Y, Amundsen T, Rosenqvist G (eds) Signals: signalling and signal design in animal communication. Tapir Academic Press, Trondheim, pp 277-300

Xia CW, Liu JY, Zhang YY (2013a) Are different song types used in different contexts in brownish-flanked bush warblers? Zool Sci 30:699-703

Xia CW, Liu JY, Alström P, Wu Q, Zhang YY (2013b) Is the soft song of the brownish-flanked bush warbler an aggressive signal? Ethology 119:653-661

\section{Submit your next manuscript to BioMed Central and take full advantage of:}

- Convenient online submission

- Thorough peer review

- No space constraints or color figure charges

- Immediate publication on acceptance

- Inclusion in PubMed, CAS, Scopus and Google Scholar

- Research which is freely available for redistribution

Submit your manuscript at www.biomedcentral.com/submit 